\title{
SOBRE EL SENTIDO DE LA TEORIA DE LOS TODOS Y LAS PARTES PARA LA FENOMENOLOGIA
}

por Agustín Serrano de Haro

La llamada a pensar las categorías ocultas que supuestamente operan en el interior de toda filosofía, no ha deparado en el caso de la Fenomenología husserliana un esfuerzo proporcionado por re-pensar las categorías ontológicas que Husserl mismo elaboró de modo explícito. Quizá el ideal de ciencia sin supuestos que la Fenomenología trascendental quiere para sí, ha contribuido también a olvidar la necesidad reconocida expresamente por la Fenomenología inicial, la de Investigaciones lógicas, de apoyarse en ciertos conceptos ontológicos. El Prólogo a la Tercera Investigación señala, en efecto, y sin ambages, la existencia de "conceptos difíciles, con los cuales operamos en la investigación destinada a poner en claro el conocimiento y que en ella han de servir en cierto modo de palancas." Y con idéntica claridad señala dicho Prólogo cuáles son estos conceptos: "La diferencia entre contenidos abstractos y concretos, que se revela idéntica a la formulada por Stumpf entre contenidos no-independientes e independientes, es de gran importancia para todas las investigaciones fenomenológicas; de suerte que parece indispensable someterla de antemano a un análisis profundo."

La referencia genérica a los "contenidos abstractos" como aquellas partes de un todo que no pueden dejar de ser parte del mismo -o de algún otro todo homogéneo- y la referencia correspondiente a los "contenidos concretos" como los complejos unitarios de partes fundamentalmente abstractas, no bastan seguramente para entender en qué sentido estos conceptos actúan como "palancas" del análisis fenomenológico de la conciencia. Sin embargo, con sólo recordar que toda afirmación de necesidad -todo juicio sintético a priori- vendría a expresar, de acuerdo con Husserl, la condición de parte por principio que afecta al objeto u objetos implicados en ella, podría atisbarse hasta dónde extiende sus dominios la teoría de los todos y las partes. Tal interpretación "mereológica" de la necesidad guiará entonces, sin duda, el análisis descriptivo de las vivencias intencionales: cada acto de conciencia es un concreto relativo, ya que integra fundamentalmente partes abstractas de géneros invariables, y la conciencia misma como corriente de actos no es sino el todo superior que resulta del necesario enlace de los actos singulares. Y al cabo, no sólo la Psicología descriptiva, aun la misma Fenomenología trascendental como Filosofía Primera, en la medida en que afirma la dependencia del mundo respecto de la vida de conciencia, habrá de ser susceptible por principio de una comprensión o interpretación "mereológica". Pues bien, ésta es la posibilidad abierta que mi tesis de doctorado, bajo el título Fenomenología trascendental y Ontología, ha tratado de hacer realidad. 
Proyecto semejante ha de empezar, por cierto, con un examen más minucioso de lo que los párrafos anteriores sugieren, de la Tercera Investigación. Entre los resultados destacables de mi estudio mencionaría aquí los siguientes: el análisis de la concepción husserliana de las partes abstractas en tres etapas -inseparabilidad, dependencia ontológica, condición de parte por principio-; el rechazo de que la mereología husserliana implique un sustancialismo, ya que, en propiedad, la dependencia rige la conexión de unas partes con otras determinadas, y no propiamente la de las partes con el todo o con alguna sección esencial del todo; la defensa de que entre partes abstractas y partes concretas impera una relación peculiar que no es la de clases complementarias; y en fin, el intento de comprension de las objetividades universales como "abstractos de segundo orden", comprensión ésta que hace de la conexión entre el momento singular y su especie una sin nexo alguno -es decir, una que no requiere ninguna teoría de la participación-. También he tratado de cubrir algunas lagunas de la Tercera Investigación, rescatando el inicio de teoría mereológica del tiempo que se encuentra en los Manuscritos de Seefeld y defendiendo que la inclusión del concreto relativo en su horizonte mundano externo presenta también necesidad no-causal.

Ahora bien, es afirmación esencial de mi trabajo la de que este poderoso marco teórico no conduce sin solución de continuidad a la Fenomenologia trascendental; que, más bien, el análisis fenomenológico que corresponde a esta teoría de los todos y las partes es, y no puede ser otro que el de la Fenomenología realista de las Investigaciones lógicas. Pues la comprensión de la dependencia por medio del concepto de parte abstracta constituye una formulación todavía demasiado general de la primera posición ontológica de Husserl. Según ésta, la dependencia ontológica no depara sólo partes por principio, sino justamente partes abstractas que se conciben como "contenidos ingredientes" -reelle Inhaltedel concreto.

"Contenido ingrediente" designa en primer término a "todo lo que el objeto tiene en sentido real", "a todo predicado real que no sea de relación"; más estrictamente, alude a las determinaciones internas del concreto excepción hecha de la temporalidad que es, más bien, la "forma" en que todos los contenidos existen. Y en su sentido último el concepto universal de contenido ingrediente implica que la consistencia del todo se agota en los contenidos ingredientes que sucesivamente pueda poseer. El todo resulta siempre y sólo de la unión de múltiples contenidos ingredientes. Dicho en los términos exactos que Husserl utiliza abundantemente y que creo haber conseguido explicitar, toda parte real de un todo define un "contenido ingrediente" dentro de una "complexión de contenidos". 
La Parte Segunda de mi trabajo trata entonces de mostrar que estos principios ontológicos obligan, en efecto, a concebir el análisis fenomenológico como análisis psicológico(-descriptivo) y que ellos son además responsables de las muy peculiares deficiencias que afectan a este análisis. La exigencia de que toda diferencia descriptiva entre actos haya de vaciarse en un contenido ingrediente de la vivencia, el cual en modo alguno implique, por lo tanto, al objeto de esta vivencia intencional o a un hipotético sujeto de ella, esta exigencia -digo- impide hacerse plenamente cargo de la penetración admirable que ya en las $\underline{I L}$ había alcanzado la descripción de la vida intencional. Las formas de la intuición sensible -percepción, conciencia de imagen, "recuerdo de presente", etc.- que señalan modos de darse el objeto mismo, y las variaciones atencionales que suponen "alguien" que hace prevalecer uno u otro de los objetos conscientes, son los casos paradigmáticos en que hago patente que "el concepto más universal de contenido, válido en todas las esferas" no puede coincidir con el concepto de "contenido en el sentido de parte ingrediente".

A esta luz, la Fenomenología trascendental, lejos de ser una posición especulativa o el resultado de un método sustantivo, se presenta con notable claridad como una precisa superación, en el análisis descriptivo de la conciencia, de la mereología general de la Tercera Investigación. Al fenómeno concreto de la intencionalidad pertenece por derecho propio el objeto que es mentado, intuido, sentido, querido, etc. Todo momento de la vivencia, todo modo noético, dice, en su propia peculiaridad interna, referencia necesaria a ese objeto que es consciente, al correlato noemático. Pero justamente esta dependencia estricta entre la vertiente noética y la vertiente noemática de la intencionalidad no hace de ellas contenidos igualmente ingredientes en un todo que atienda a la forma indiferenciada de una complexión. Como afirmo en mi estudio, "la articulación noético-noemática de la intencionalidad muestra una forma de todo relativo en que los integrantes abstractos, en lugar de fundirse entre sí, se oponen; en lugar de compenetrarse o enlazarse, se hacen frenten.

Tengo para mí que el análisis mereológico de la correlación intencional, que desarrollo en la Tercera Parte de mi estudio, es el centro de mi trabajo. $Y$ en particular, el examen de la constitución intencional como forma de unión entre la vertiente noética y la noemática de la correlación es el punto culminante del acercamiento mereológico a la Fenomenología. La constitución intencional sería la única forma de unión que hace inteligible una dependencia necesaria que se articula, sin embargo, sobre la "trascendencia" de todo núcleo noemático respecto de las vivencias en que se cumple su propia dependencia (trascendencia "relativa"). La inclusión del nóema a título de parte no- ingrediente de la 
conciencia, de inmanencia ideal que no se temporaliza en ningún curso discreto de vivencias, exige pensar su identidad como el sentido primitivo que la vida de conciencia, ante todo en su fondo pasivo, constituye. $Y$ en consecuencia, el idealismo trascendental resulta la única manera de asumir el análisis noético-noemático de la intencionalidad. Sin la noción de nóema no se consuma la descripción de la intencionalidad. Pero con ella esta descripción es ya teoría monadológica, no ontología de determinados seres mundanos.

A mi modo de ver, la cuestión más grave que suscita el desarrollo de mi trabajo no es la de si la teoría de los todos y las partes convierte la Fenomenología trascendental en ciencia dogmática, en una ontología, tan especial como se quiera. Cualquier "meditación fundamental" que pretendiese retroceder a un terreno previo a toda categorización, topa con la aporía de que lo que aparece en tal meditación está dotado de unidad, es decir, se presenta de una u otra manera como un todo. Creo, más bien, que el problema último reside en saber si la meditación fundamental acerca de la vida de conciencia, que Husserl realiza, no debe demasiado a la tesis de que la consistencia de un todo le viene siempre dada por sus componentes, sean éstos contenidos ingredientes o no lo sean. Me pregunto si la evidencia radical acerca de mi propia existencia consciente no habla también de una cierta originariedad irreductible en la posición de mí mismo, la cual no quedaría suficientemente recogida en la teoría del yo como polo permanente de habitualidades y afecciones. En definitiva, no estoy seguro de que el concepto fenomenológico de mónada se asiente sobre base firme mientras todo posible sentido, subjetivo u objetivo, toda posible afirmación de necesidad haya de interpretarse como afirmación estrictamente "mereológica", antes que propiamente "holológica" -esto es, referida al sentido originario y primitivo del todo- $Y$ permítaseme manifestar mi sospecha de que las extremas dificultades que encuentra el análisis fenomenológico para justificar la intersubjetividad trascendental, acaso puedan tener que ver con este oscuro matiz de que el todo que es la conciencia quizá no agota nunca su sentido en la conexiones de unas partes para con otras y de unos períodos para con otros; como si yo trascendiese siempre de alguna manera todo lo que me atribuyo, y lo mismo ocurriese con el otro yo. 